\title{
DETECTION OF THE R-PHASE IN Ni-Ti SHAPE MEMORY ALLOYS
}

\author{
K. GOUBAA ${ }^{*, * *}$, M. MASSE ${ }^{*, * *}$ and G. BOUQUET ${ }^{*, * *}$ \\ *Ecole Nationale Supérieure de Chimie de Paris, 11 rue Pierre et Marie Curie, F-75231 Paris cedex \\ 05, France \\ ${ }^{* *}$ Centre d'Etudes de Chimie Métallurgie, 15 rue Georges Urbain, F-94407 Vitry sur Seine cedex, \\ France
}

\begin{abstract}
In NiTi based shape memory alloys, a transient phase, called R-phase, occurs on cooling before the martensitic transformation. The detection of the R-phase seems to be dependent on various parameters and particularly on experimental technique. Indeed, in this study we examine the sensitivity of various methods as internal friction, transmission electron microscopy, X-ray diffraction, electrical resistance, differential scanning calorimetry. However thermal treatments and chemical content are also taken into account.
\end{abstract}

\section{Introduction}

According to numerous studies concerning NiTi shape memory alloys, the R-phase of these materials appears as a phase much debated (1-8) because of an occurrence depending on various parameters as the chemical content of the alloys or as thermal treatments. In this study we try to clarify the possibility of detecting the $\mathrm{R}$-phase in given $\mathrm{NiTi}$ or $\mathrm{NiTiCu}$ alloys by means of various experimental methods : transmission electron microscopy, $\mathrm{X}$-ray diffraction, electrical resistivity, internal friction, differential scanning calorimetry.

\section{Experimental results}

The chemical content (at. \%) of the alloys studied here are the following : NiTi : $48 \% \mathrm{Ni} 52 \% \mathrm{Ti}, \mathrm{NiTiCu}$ : $46,2 \% \mathrm{Ni}, 49,6 \% \mathrm{Ti}, 4,2 \% \mathrm{Cu}$. NiTi alloys exhibit the particularity to be $\mathrm{Ti}$ rich in order to increase the As temperature. Our experimental results will concern successively NiTi and NiTiCu alloys.

\section{NiTi alloys}

\section{Internal friction}

Internal friction results are reported in Fig. 1 where we show the $\mathrm{Q}^{-1}$ spectra obtained on heating and on cooling in a temperature range between $0^{\circ} \mathrm{C}$ and $180^{\circ} \mathrm{C}$. Each spectrum is characterized by a $\mathrm{Q}^{-1}$ maximum related to the martensitic transformation. No anomaly can be detected suggesting the possibility of an other phase transformation. Consequently, in this case, internal friction seems inefficient in proving the R-phase arising if it exists. 


\section{Transmission Electron Microscopy (T.E.M.)}

According to the previous $\mathrm{Q}^{-1}$ results the direct martensitic transformation takes place between 80 and $60^{\circ} \mathrm{C}$. If a R-phase transition would have to be observed, it would occur at temperatures higher than $80^{\circ} \mathrm{C}$. Surprisingly, T.E.M. observations have shown that R-phase is observable without care of temperature conditions of the specimen in the microscope. Furthermore no peculiar thermal treatmemi was performed on the sample, except a reference annealing at $800^{\circ} \mathrm{C}$ under high vacuum. A characteristic electron diffraction pattern of the R-phase is reported in Fig. 2 where we note a distorted b.c.c. cell accompanied with superlattice spots. These spots an generally observed at $\frac{1}{3}\left\langle 110^{*}\right\rangle, \frac{1}{3}\left\langle 111^{*}\right\rangle, \frac{1}{3}\left\langle 112^{*}\right\rangle, \frac{1}{3}\left\langle 213^{*}\right\rangle, \frac{1}{3}$ $<210 *>$ and are related to a charge density wave (9).

\section{X-ray diffraction}

X-ray diffraction experiments, performed with temperature scanning, have confirmed the occurrence of the $\mathrm{R}$-phase in NiTi alloys. The results are reported in Fig. 3 where we follow the evolution of the (110) diffraction line of the b.c.c.. structure. A shoulder is detected at $55^{\circ} \mathrm{C}$ and at about $45^{\circ} \mathrm{C}$ this line splits into two diffraction lines belonging to the R-phase.

\section{Electrical resistance}

The electrical resistance of cylindrical specimens $(\varnothing=2 \mathrm{~mm})$ was determined as a function of temperature. According to litterature (10-12), on cooling, the R-phase leads to an electrical resistance increase, inversely to the effect of the martensitic phase which involves a resistance decrease. In the case of $\mathrm{NiTi}$ alloys this experimental technique is able to detect the R-phase providing that heat cycling was performed as shown in Fig. 4.

\section{Differential Scanning Calorimetry (D.S.C.)}

Inversely to the previous experimental methods, the R-phase of NiTi alloys is detectable only after thermal treatments. For example the curve presented in Fig. 5 shows clearly the R-phase arising revealed, on heating, by a double maximum while on cooling the effect is reduced to a shoulder on the main maximum. The preliminary thermal treatment consisted in an annealing at $250^{\circ} \mathrm{C}$ during 50 hours.

\section{$\underline{\text { NiTiCu alloys }}$}

\section{Internal friction}

The internal friction behaviour of NiTiCu alloys is clearly different from the one of NiTi. Indeed, on the spectra in Fig. 6 we note, on heating, three maxima $P_{1}, P_{2}, P_{3}$, but only two, $P_{2}^{\prime}, P_{3}^{\prime}$ on cooling. The maximum $P_{1}$ is not observed on cooling and on the basis of other results (13) the maximum $P_{1}$ is attributed to martensitic variants reorientations. The maximum $\mathrm{P}_{2}$ and $\mathrm{P}_{2}$ are associated with the inverse and direct martensitic transformation respectively while $P_{3}$ and $P_{3}$ are ascribed to the $R$-phase occurrence. We note, in Fig. 6, the effect of the heating rate which permits to reveal the R-phase with much more sensitivity at higher rates.

\section{Transmission Electron Microscopy}

T.E.M. observations in the case of NiTiCu alloys bring informations somewhat different from those of NiTi. Indeed, the R-phase is also detected but the corresponding electron diffraction patterns consist in a distorted cell without superlattice spots. Furthermore the distorsion observed is not rhomboedral 1 because of different values for $\mathrm{d}^{*} 001$ and $\mathrm{d}^{*} 100$ as shown in Fig. 7.

\section{Electrical resistance}

Electrical resistance results exhibit simple evolution curves and no anomaly, due to the R-phase, can be truly detected. In these conditions the variations are principally associated with the martensitic transformation (Fig. 8). 
Differential Scanning Calorimetry

As in the case of NiTi alloys, NiTiCu samples need thermal treatments in order to reveal the R-phase (Fig. 9). The curves reported in FIG.9 were obtained for a sample annealed at $500^{\circ} \mathrm{C}$ during 160 hours.

\section{Discussion}

According to our results it appears that, whatever the chemical nature of the alloy is, the R-phase seems to be an unavoidable transformation stage and the fact that this phenomenon is observable, or not, depends on the temperature difference relative to the martensitic transformation. Among the various experimental methods presented here and used to detect the R-phase, each one presents a specific sensitivity. Internal friction could appear as the most sensitive one because it detects not only the R-phase, but also the martensitic transformation and additionnal phenomena as martensitic variants reorientations. Nevertheless care must be taken for some experimental conditions as the heating rate. In the case of T.E.M. observations, the R-phase is observable in each alloy but the diffraction patterns exhibit different particularities. Before concluding that the respective R-phases of these alloys are themselves different, more informations would be necessary about the specimen temperature in the microscope. May be a slight temperature difference could lead to the apparition of superlattice spots in NiTiCu alloys.

The last remark concerns the need, in some cases, to perform thermal treatments in order to reveal the Rphase. In these conditions, the question is to know if such a treatment induces the R-phase nucleation or if it increases the difference, $\Delta T_{R-M}$, between the respective nucleation temperatures of the $R$-phase and the martensite, leading to an easier experimental detection. We think that it is this second effect which plays a prominent role according to results obtained on other materials (14). Thus, thermal treatments appear as mean to separate interfering phenomena and a similar effect seems result from changing the chemical content of alloys.

\section{Conclusion}

The main result of this study is that, whatever the alloy is, NiTi or NiTiCu, the R-phase occurs and its detection depends, on one hand, on the experimental technique used, and on the other hand, on the possibility of interference between the R-phase and the martensite. Thermal treatments or chemical contents appear as parameters allowing a separation of these interfering phenomena by shifting their respective nucleation temperatures. The martensitic transformation shift is more sensitive to thermal treating than the R-phase. Differences observed in the crystalline structure of R-phases suggest the possibility of different stages in the processes transforming the b.c.c. phase into martensite but more experimental results are needed.

\section{References}

1) WAYMAN C.M., Int. Meet. on Advanced Materials, 9 (1989) 63

2) XUEMIN L., HSU T.Y., Mat. Sc. Eng., 91 (1987) 189

3) NISHIDA M., MONNA T., J. de Phys., C4, 43 (1982) 225

4) HWANG C.M., WAYMAN C.M., Scripta Met., 17 (1983) 381

5) HWANG C.M., WAYMAN C.M., Scripta Met., 17 (1983) 385

6) HWANG C.M., MEICHELE M.E., SALAMON M.B., WAYMAN C.M., Phil. Mag., A 47 (1983) 9

7) HWANG C.M., MEICHELE M.E., SALAMON M.B., WAYMAN C.M., Phil. Mag., A 47 (1983) 31

8) SALAMON M.B., MEICHELE M.E., WAYMAN C.M., Phys. Rev., B 31 (1985) 7306

9) MICHAL G.M., MOINE P., SINCLAIR R., Acta Met., 30 (1982) 125

10) DAUTOVICH D.P., PURDY G.R., Can. Met. Quart,. 4 (1965) 129

11) HUNG C.L., KAPL.OW R., Met. Trans., A. 12 (1981) 2101

12) MIYAZAKI S., OMNI Y., OTSUKA K., SUZUKI Y., J. de Phys., C4, 12 (1982) 255.

13) GOUBAA K., ORLIONNET V., MASSE M., BOUQUET G., Scripta Met. 22 (1988) 1023 ,

14) JORDAN L., GOUBAA K., MASSE M., BOUQUET G. This conference. 


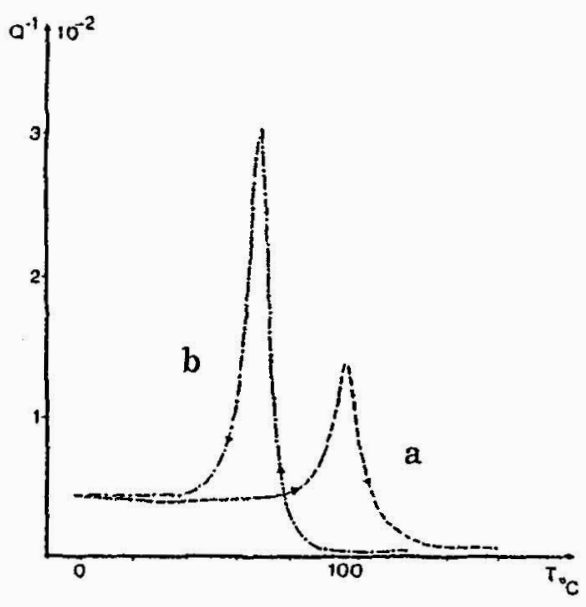

Fig.1 Internal friction spectra of NiTi alloys as a function of temperature. a) Evolution on heating, b) evolution on cooling.
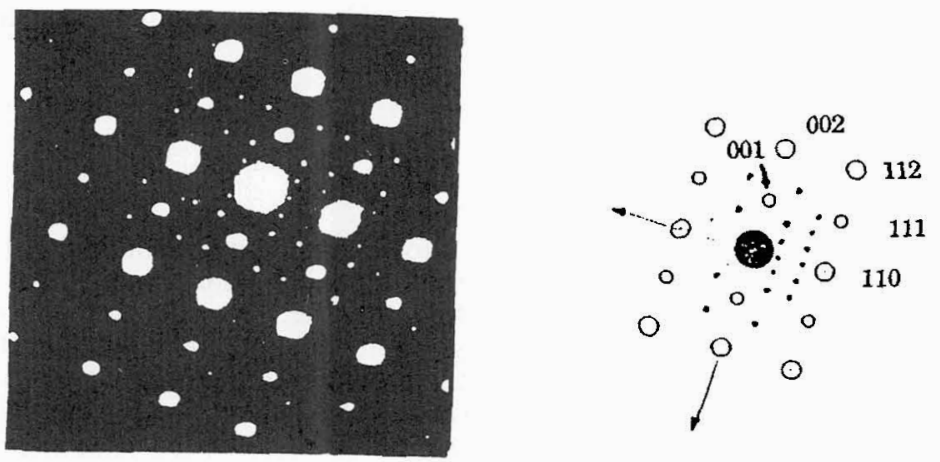

Fig.2 Electron diffraction pattern of NiTi alloys showing supperlattice spots of a distorted cell characteristic of the R-phase.
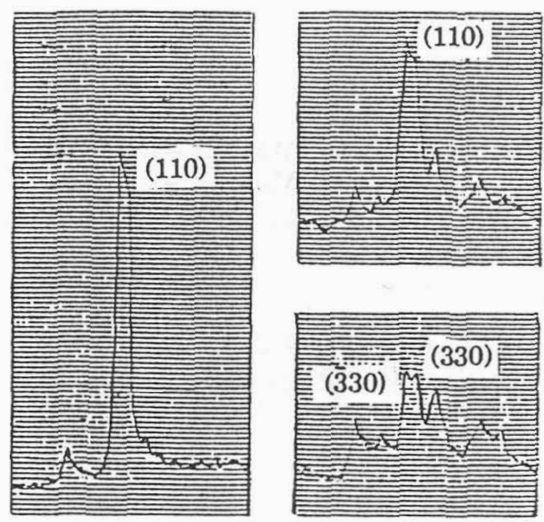

Fig. 3 X-ray diffraction spectra showing the evolution of the (110) line of the b.c.c. high temperature structure splitting into two lines characteristic of the R-phase: ( 330$)$,

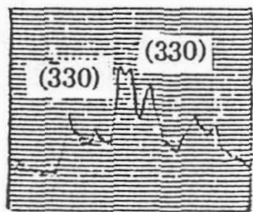
(330). 


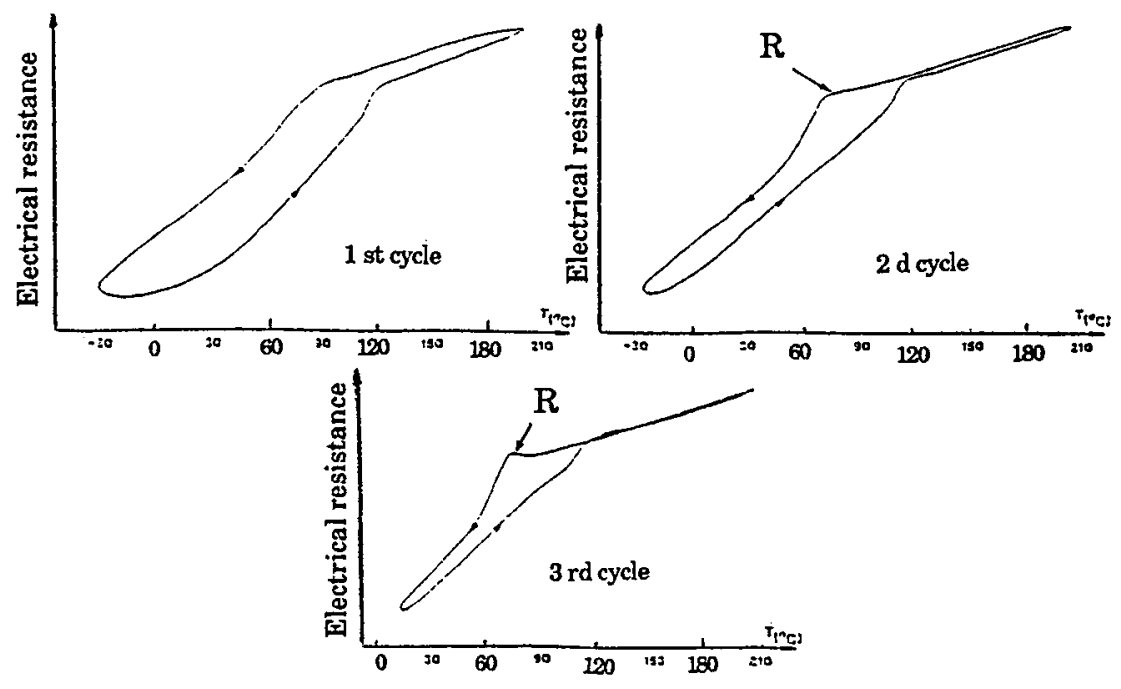

Fig. 4 Electrical resistance evolution as a function of temperature. The R-phase is detected by the development of a maximum on the curve.

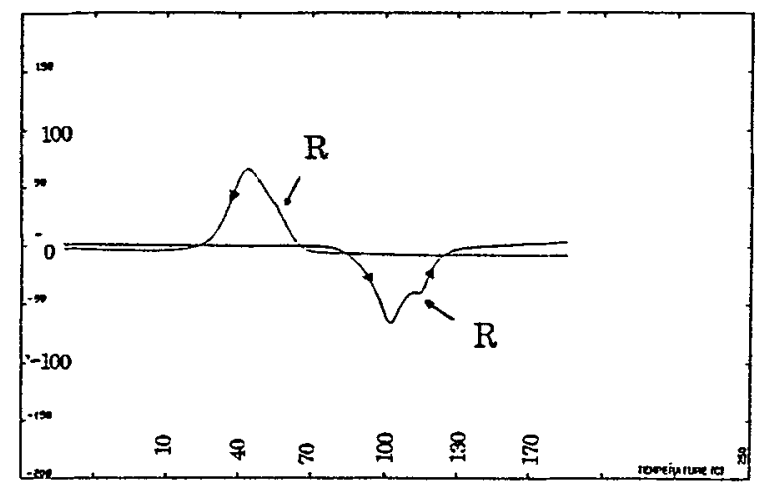

Fig. 5 Differential Scanning Calorimetry of NiTi alloys. The R-phase leads to a shoulder on the curve on cooling and to two maxima on heating.

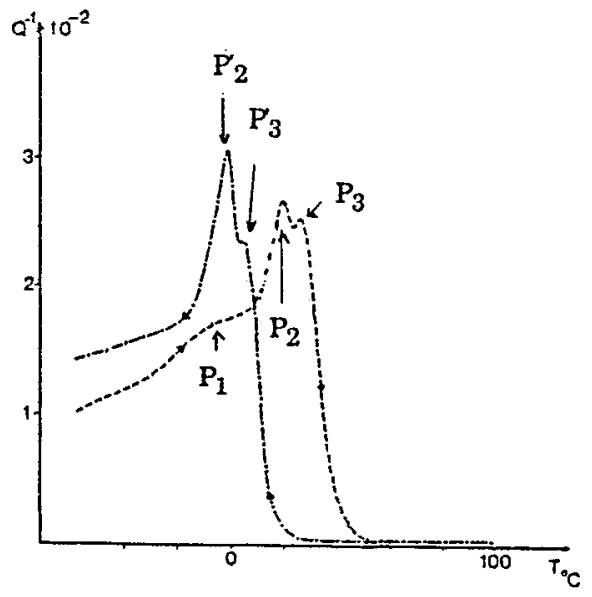

Fig. 6 Internal friction of NiTiCu alloys. Three maxima are observed on heating: $\mathrm{P}_{1}, \mathrm{P}_{2}, \mathrm{P}_{3}$, two on cooling: $\mathrm{P}_{2}, \mathrm{P}_{3}$. 

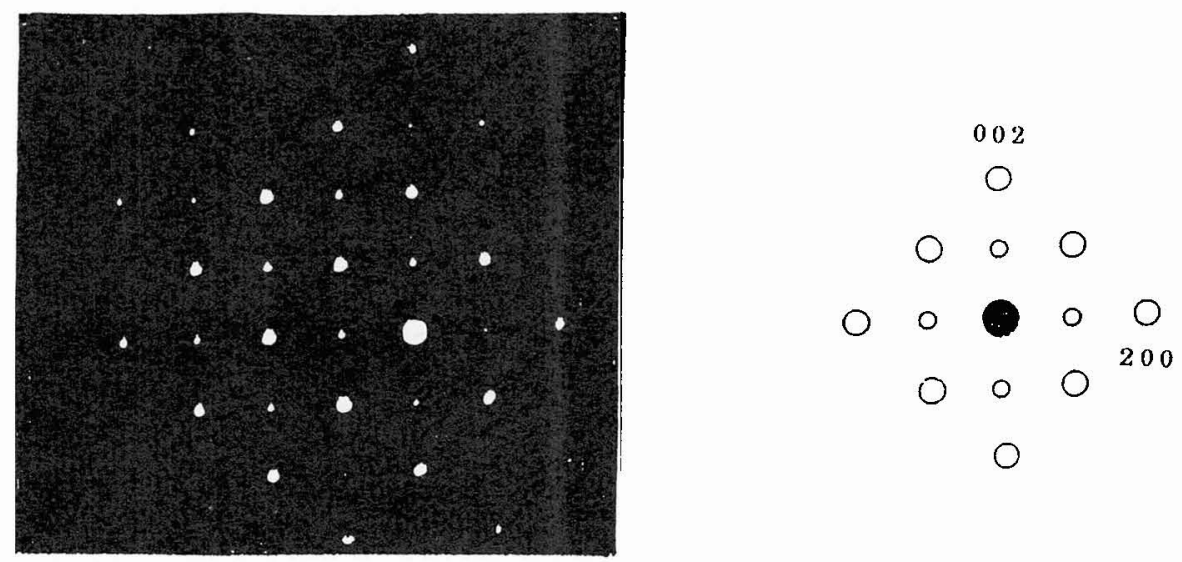

Fig. 7 Electron diffraction pattern of Ni'liCu alloys showing the existence of the R-phase: typical $\mathrm{CsCl}$ distorted structure.

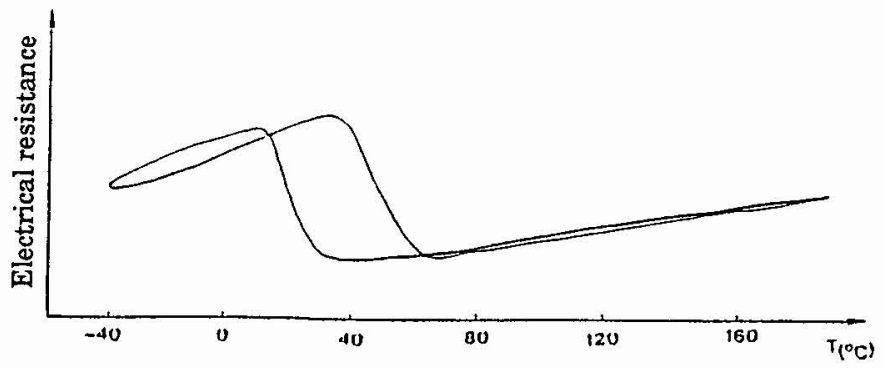

Fig. 8 Electrical resistance evolution of Ni'liCu alloys exhibiting no particular anomaly.

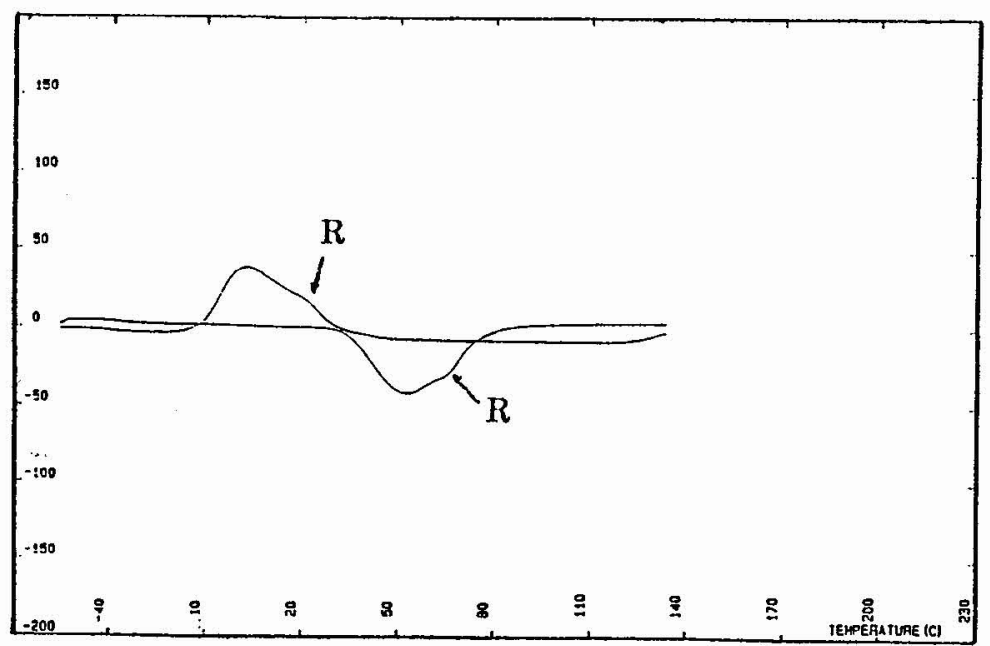

Fig. 9 Differential Scanning Calorimetry of Ni'TiCu alloys . The R-phase is detected by shoulders on the curves. 